Apart from the reception at the Reichstag, the Congress was entertained by Germany, by the State of Prussia, and by the town of Berlin, in addition to a gala night at the Opera and the usual public and private hospitality. Fortunately, the English delegation was not only the largest, but also most thoroughly representative in character, and it played an important part in the deliberations. It was all the more to be regretted that Mr. Dunlop, the prime mover in the Conference, was himself prevented by ill-health from being present.

Naturally, the opportunity was not lost to show the visitors at the great evening festival some of the modern tendencies of Germany. Chief amongst these is the outdoor movement with a minimum of clothing and the cultivation of physical fitness. Most charming displays were given by girls and by young men. Of extraordinary interest was the final display of representatives of the German States in their national costumes and dances: the subordination of Prussia and the accentuation of the Rhine, of the Franks, of the Bavarians, scarcely seemed accidental. The enthusiasm when the president joined his native Bavarians was a fitting climax to a most remarkable evening, which to the knowledgable gave much room for thought, both retrospective and prospective.

Members of the Congress were provided with a quite unusual amount of literature, much of it of a permanentnature, giving information as to the power projects of Germany and of Europe. We have become used to the amazing development of cheap electric power either from coal or from water in the United States or in Canada: what the Congress should bring home is that similar developments are taking place on the Continent. Cheap electricity can do so much for the needs and comfort of mankind that no country of the first rank can afford to let its citizens be without it -it should be available in every village, in very farmhouse, throughout the land, as will soon be the case in France; it should be possible to carry out every power operation on the farm and in the living house, as well as in the factory, by its aid. The presence of so many of our leading electricians at the Congress shows that they are alive to the problems, but we fear the country as a whole fails to realise how far behind Britain is in the use of electricity per capita. We have very little water power, but our engineers are at least capable of emulating the remarkable results achieved at Chicago, where something less than a pound and a half of coal per kilowatt hour is required.

It is often forgotten that the production of electric power is as much a water as a coal problem, about 400 tons of cooling water being required for every ton of coal burnt, so that suitable sites for very large stations are not always easy to find.

The scope of the Congress stretches of course far beyond electric power ; the carbonisation of coal either at high or low temperatures; the problems of oil, its refining and cracking, all come within its scope. In the end the goal is the same, to turn the heat latent in coal or oil, lignite or peat, with the highest degree of efficiency into energy, into power. The transformation in early days was not an easy one, and as represented in percentages highly inefficient. Amazing progress has been made in improving the efficiency; the World Power Congress can but accelerate this. E. F. Arustrong.

\title{
Irregularities in the Annual Variation of Temperature in London.*
}

$\mathrm{T}$ $\mathrm{HE}$ average temperature of London is lowest about the middle of January and highest towards the end of July, but in any one year. the temperature rises and falls irregularly, and the coldest day may occur in February or March instead of January, the warmest in August or September instead of July. Even when thirty or forty years are combined, some of these irregularities remain, and it is an interesting question whether, as the record is extended, the curve of temperature will tend more and more to a smooth annual variation, or whether certain irregularities are inherent in the climate and will always remain. This question was first examined in detail for Britain by Alexander Buchan, who recorded his conclusions in 1869 as follows :

"Deductions from all observations hitherto made show that... there are certain periods more or less well defined, when the temperature, instead of rising, remains stationary or retrogrades; instead of falling, stops its downward course, or even rises; and at other times falls or rises respectively for a few days at a more accelerated speed than usual." Synopsis of a paper read at the Royal Meteorological Society on
June 18, by Dr. C. E. P. Brooks and S. T. A. Mirrlees, with some June 18 , by Dr. C. E. P. Brooks and
references to the subsequent discussion.

Buchan picked out six cold and three warm periods, as follows :

Cold Periods.
1. February 7-14
2. April 11-14
3. May 9-14
4. June 29-July 4
5. August 6-11
6. November 6-13

Buchan's work was based in the first place on data for Scotland about 1860, but his results have been tacitly assumed to apply over the whole of the British Isles, and the 'Buchan cold and warm spells' have attained some celebrity. A repetition of the investigation seemed to be called for, using a long series of records for London.

Daily means of temperature at Kew Observatory based on hourly readings were formed for the two nearly equal intervals 1871 to 1900 and 1901 to 1929. These showed many small irregularities, and as warm and cold 'spells' were being sought rather than individual days, it seemed advisable to smooth the data. This was done by forming overlapping five-day means, for example, January $1-5,2-6$, etc., each five-day mean being entered against the middle day. The two curves obtained 
in this way were compared with a standard curve representing the generalised annual variation, which was obtained by harmonic analysis of the twelve monthly means ; the first two terms, representing the annual and semi-annual waves, were found to be sufficient for this purpose. The results are shown in the main curves of Fig. 1.

This figure shows that the five-day means of temperature during both periods oscillate irregularly about the smooth curve, but in general keep rather close to it. In most months the irregularities in 1871-1900 are quite different from those in warm spells, for though the third, December 3-14, is not supported, the first two fall on dates when both curves are definitely high. An examination of the average temperatures at Kew Observatory for 59 years therefore accords no support for any of Buchan's cold spells, but suggests that the first two warm spells may have been well founded.

Apart from this, the curves show several points of interest. In December and January the average temperature since 1901 has been about $2^{\circ} \mathrm{F}$. above the average for 1871-1900, a difference associated with the prevalence of warm winters during the

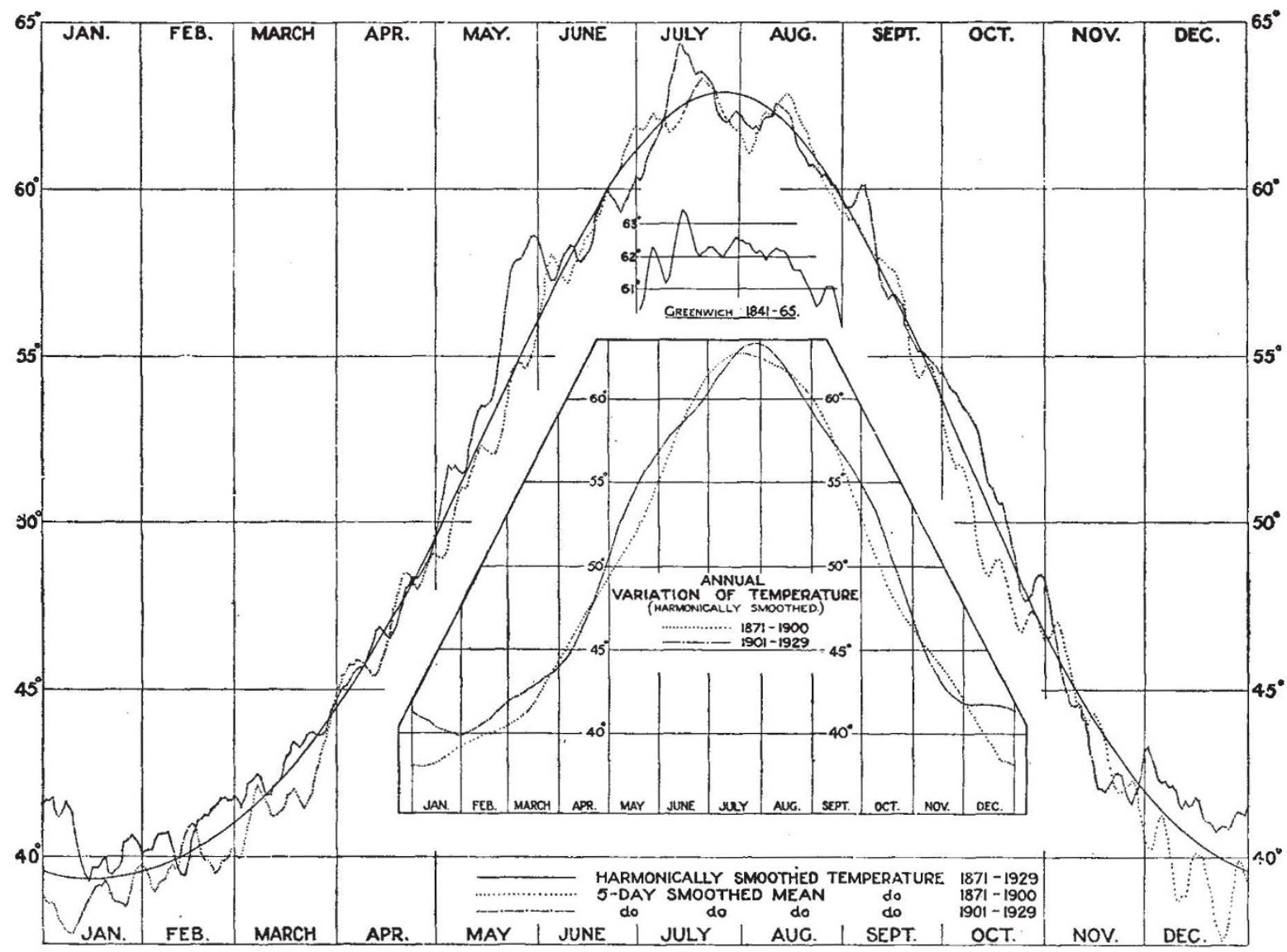

FiG. 1.-Temperature curves derived from Kew observations. (Reproduced by courtesy of the Royal Meteorological Society.)

1901-1929, showing that they represent temporary or 'accidental' abnormalities and not permanent features of the climate. In particular, the curves seem to show quite definitely that the "Buchan cold spells ' do not recur regularly in London. The first, February 7-14, is represented, it is true, by a marked dip in 1901-1929, but the curve for 18711900 during those days rises rapidly to a maximum. In April 11-14 and May 9-14 neither curve shows any abnormal feature. In June 29-July 4 the curve for 1901-1929 is low but rising steadily, while that for 1871-1900 is definitely high, indicating a warm rather than a cold spell. In August 6-11 both curves are rising steadily, and again in November 6-13 neither shows any special anomaly. The figure is rather more favourable to Buchan's present century. The magnitude of this change is clearly brought out by the lower inset diagram, which shows the results of harmonic analysis of the two periods separately. Not only have recent winters been warmer, but also the generalised minimum has been displaced from early in January to the end of the month, while at the same time the generalised maximum has been retarded from the middle to the end of July and the annual range has decreased, all indications that the climate has become more oceanic. Again, in 1901-29 temperature rose very rapidly during the latter half of May, and on May 30 the curve reaches a level which is not found again until June 17 , a truly remarkable feature to occur in the 29-year averages for a season during which temperature should be rising 
steadily. A somewhat similar distortion, though less pronounced, occurs in early October, when the curve for 1901-29 shows a definite slackening of the autumn fall of temperature.

The third point of interest concerns the temperatures of high summer. Both curves show a marked swing, with a range of $2^{\circ} \mathrm{F}$., from a maximum in mid-July to a minimum early in August and back to a second maximum in mid-August. This feature was of such interest that the five-day means of temperature at Greenwich during July and August were extracted for the period 18411865, and are shown in the upper inset of Fig. 1. Here the July maximum is again shown, but the minimum early in August does not appear and the August maximum is reduced to very small proportions. The impression left by a comparison of these three curves is that there is a definite tendency for a warm spell to occur in mid-July, after which there is a period during which temperature oscillates irregularly until the autumen fall sets in after the middle of August.

Although the comparison of curves showing averages over a number of years is the simplest method of approaching a problem of this nature, the results are sometimes misleading. The more interesting abnormalities revealed by Fig. 1 were accordingly studied year by year, in order to determine whether they are regular characteristics of the climate or whether they merely reflect a few outstanding events. In the first place the 'Buchan cold spells ' in February, April, and May were examined to determine if there was any definite tendency for temperature in individual years to fall to minima on those dates. The results were entirely negative ; the chance that one of these periods will be unseasonably cold is exactly equal to the chance that it will be unseasonably warm. If we allow a 'grace' of two days on either side, the individual curves show that temperature actually rose to a maximum more often than it fell to a minimum.

The warm period in mid-July affords an example of the fallacy sometimes introduced by reasoning from averages. During the whole 59 years the average temperature was highest on July 15-19, but when the individual years were examined, this predominance was found to rest entirely on four years, 1876, 1881, 1900, and 1921, while temperature was below the smooth curve on 30 occasions out of the remaining 55 . The second crest on the curve occurs on August 14-18, and this period was abnormally warm on 32 occasions, cool on 27 , a negligible difference.

The general conclusions drawn from the investigation were summed up as follows: "On the whole it seems improbable that there exists in our climate an abiding tendency for any part of the year to be either abnormally warm or abnormally cold for the season. It does seem, however, that such tendencies may spring up suddenly, persist for ten or twenty or thirty years, and as suddenly and mysteriously vanish. Any positive conclusions as to these spells are valid only for the time and place of their occurrence, and cannot be applied to other times or places. Thus, while Buchan's cold and warm spells were probably true for Scotland in the 1860 's, they are certainly not true for London in the twentieth century."

In the discussion which followed the paper, $\mathrm{Mr}$. D. Brunt objected that 'cold spells 'were on some occasions limited to one or two days, and these would be masked by the use of five-day means. He also thought that the investigation should have dealt with individual years rather than with averages over long periods. It was suggested that a possible explanation of the persistent belief in Buchan's cold and warm spells was that when they did occur, they had a tendency to fall on or near Buchan's dates, though in many years they were absent. On the other hand, Mr. Mirrlees thought that the belief had persisted because meteorologists had devoted a great deal of effort to explaining the occurrence of such spells, and little or none to finding out whether there was anything to explain. Apart from this, a few of the explanations advanced were sufficiently plausible, for example, pressure changes set up by differential warming of the earth's surface, and outbreaks of polar ice, but as usually happens when theorising loses touch with facts, some of the theories were merely absurd. They included cosmic dust from meteor showers in the earth's atmosphere, cometary matter between the earth and the sun, the latent heat of freezing and thawing of Russian rivers, the varying absorption of radiation owing to changes of humidity, and mirabile dictu, the meteorological effects of newly expanded foliage in spring.

C. E. P. Brooks.

\section{Crime Statistics of England and Wales.}

U RIMINAL statistics, apart from their primary purpose, usually afford some interesting sidelights on social habits and in particular on any changes which are taking place in the daily life of the community with which they deal. For example, in the criminal statistics of England and Wales for the year 1928 (Cmd. 3581, H.M. Stationery Office, price $4 s$. net) an attempt has been made to gauge the effect of the coming of the 'motor age' on crime. Taking the year 1928 and comparing the figures for the crime of 'breaking in' with those of 1911 it appears that, while the figures for the metropolitan area are practically stationary, in the home counties they show an increase of 437.8 per cent, and over the whole of England and Wales outside the metropolitan area the increase in boroughs and cities is 87 per cent, but in the counties it is 137 per cent. This is attributed to the increased use of the motor-car, which is thought to have acted in two ways. Greater numbers of the population have been enabled to live outside urban areas and premises are more often left unoccupied, while an increase in the 'all in ' policy of insurance has tended to reduce precaution. On the other

No. 3167 , VoL. 126] 